\title{
PHOTOVOLTAIC MAXIMUM POWER POINT TRACKING USING SEPIC CONVERTER
}

\author{
Yousry Atia \\ Electronics Research Institute, PV Cells Dept, \\ El-Tahrir St., Dokki, 12311-Giza, Egypt
}

\begin{abstract}
In this paper a maximum power point tracking (MPPT) system based on the single ended primary inductor converter (SEPIC) and hill-climbing approach is introduced. SEPIC converter is a comprehensive buck-boost converter and has minimum ripple content in the input current that suitable for PV application. The proposed MPPT system is designed and components of SEPIC converter are sized and selected. The controller is so fast and no fluctuation around the MPP is introduced. A current and voltage of the PV array are sensed and a pulse width modulation (PWM) signal is produced from the controller to control the duty ratio of the converter. The simulation results show that three tests are carried out on the system; a suddenly insolation level increasing, decreasing, and load resistance variation. The controller establishes robustness for all the three cases and the maximum power available from the PV array are transferred to the load irrespective of load or environmental condition variations.

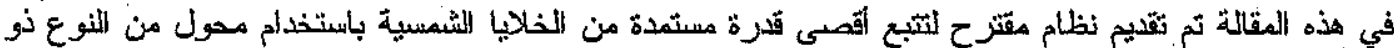

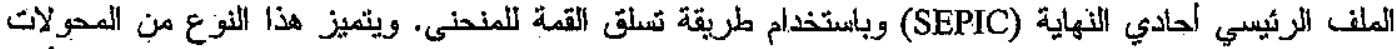

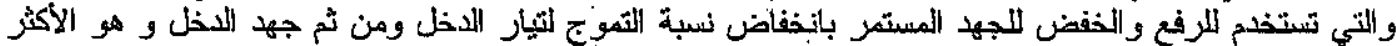

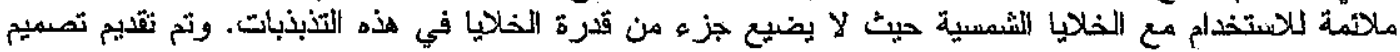

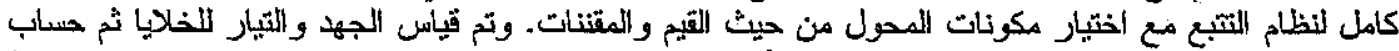

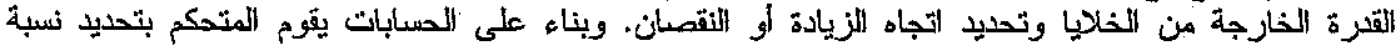

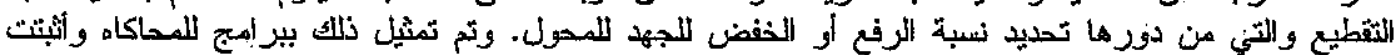

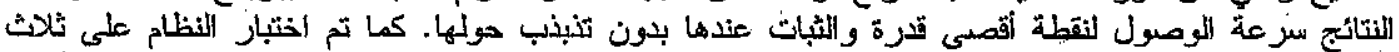

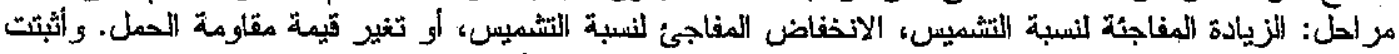

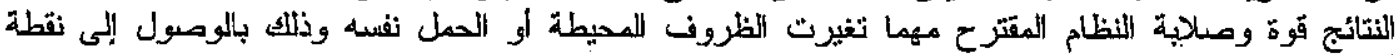
أقصىى قدرة بسر عة وثبات.
\end{abstract}

Keywords: Maximum Power Point Tracking, SEPIC Converter, DC/DC Converter.

\section{INTRODUCTION}

As the oil prices increase in these days and the fossil fuel are dwindling fast, the photovoltaic (PV) energy offers an alternative source of energy. It is clean, free, renewable, abundant, and distributed throughout the earth; the only drawback is that the initial installation cost is considerably high [1]. The maximum power point tracking (MPPT) of a photovoltaic array is usually an essential part of the PV system [2]. The maximum power point tracking is applied to PV systems in order to match the solar array output with the given load extracting the maximum available power from the PV system under all metrological and operating conditions. Different maximum power tracking schemes have been proposed by using different control strategies [1-13]: As such, many MPPT methods have been developed and implemented. The methods vary in complexity, sensors required, convergence speed, cost, range of effectiveness, implementation hardware, popularity, and in other respects [2].

\section{PV SYSTEM PERFORMANCE}

The photovoltaic system characteristic curves are a family of non linear curves. These curves are a relation between current and voltage (I-V); and between power and voltage (P-V) curves. These curves are depends on sun light insolation level and the cell temperature.

\subsection{PV System Model}

The PV solar cells are basically $p-n$ junctions. In the dark, their (I-V) characteristic is similar to that of a diode. The model (Figure 1) includes an ideal diode, and ohmic losses series resistance [14].

Light creates inside the junction electron-hole pairs. The effect of these carriers corresponds to an additional current source $\left(\mathrm{I}_{\mathrm{L}}\right)$ proportional to the 
incident radiation and connected in parallel on the ideal diode as shown in Fig 1.The cell current is:

$I=I_{L}-I_{D}$

$I=I_{L}-I_{0}\left(\exp \frac{q\left(V-I R_{S}\right)}{m K T}-1\right)$

$V=-I R_{s}+\frac{1}{\Lambda} \ln \left(1+\frac{I_{L}-I}{I_{o}}\right)$

Where: $\Lambda=\frac{q}{m K T}$

I the cell output current.

$\mathrm{V}$ The cell terminal voltage.

$\mathrm{R}_{\mathrm{S}}$ Cell series resistance.

$I_{0}$ The diode reverse saturation current.

K Boltizman's Constant.

$\mathrm{T}$ The cell surface absolute temperature.

$q$ the electron charge.

$m$ the completion factor.

For PV solar generator with $\mathrm{N}_{S}$ series cells and $\mathrm{N}_{\mathrm{P}}$ parallel cells the generator model will be:

$V_{g}=-I_{g} R_{s g}+\frac{1}{\Lambda_{g}} \ln \left(1+\frac{I_{L g}-I_{g}}{N_{p} I_{o}}\right)$

$R_{s g}=\frac{R_{s} N_{S}}{N_{p}}, \Lambda_{g}=\frac{\Lambda}{N_{s}}, I_{L g}=I_{L} * N_{p} * S$,

$I_{o g}=I_{o} * N_{p}$

$S \quad$ is the sun light insolation level $=0: 1$

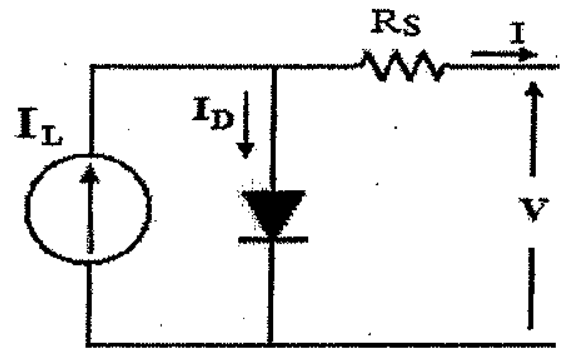

Fig. 1 The PV solar cell model.

\subsection{PV System Characteristics}

Equation (3) can be simulated with varying sun insolation levels and cell temperature to produce a family of I-V and P-V characteristics curves as shown in Figure 2.

\subsection{Load Characteristics and Problem Definition}

The load on the PV solar cell generator may be a dynamic or a static load. A dynamic load has varying characteristics all over the operating range, whereas the static load has stable characteristics allover operating range. A resistive load is static and linear characteristics allover the operating range. If the load line intersects the PV characteristic curve at the maximum power point, so the matching is $100 \%$ between the load and the PV generator. But with varying operating conditions such that varying insolation level or temperature, or varying load resistance, the matching no longer exists. So we need to transfer the load resistance to another value to be seen from the PV generator side as $100 \%$ matching at all operating conditions.

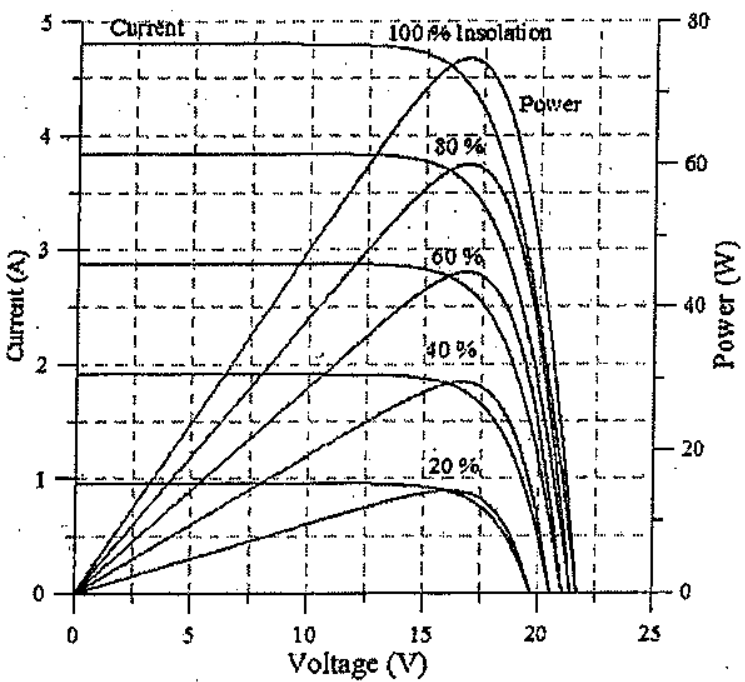

Fig. 2 PV system characteristics for different insolation levels.

Figure 3 shows a varying resistive load family of characteristics curves that intersects the I-V curves for solar cell generator at distinct operating points.

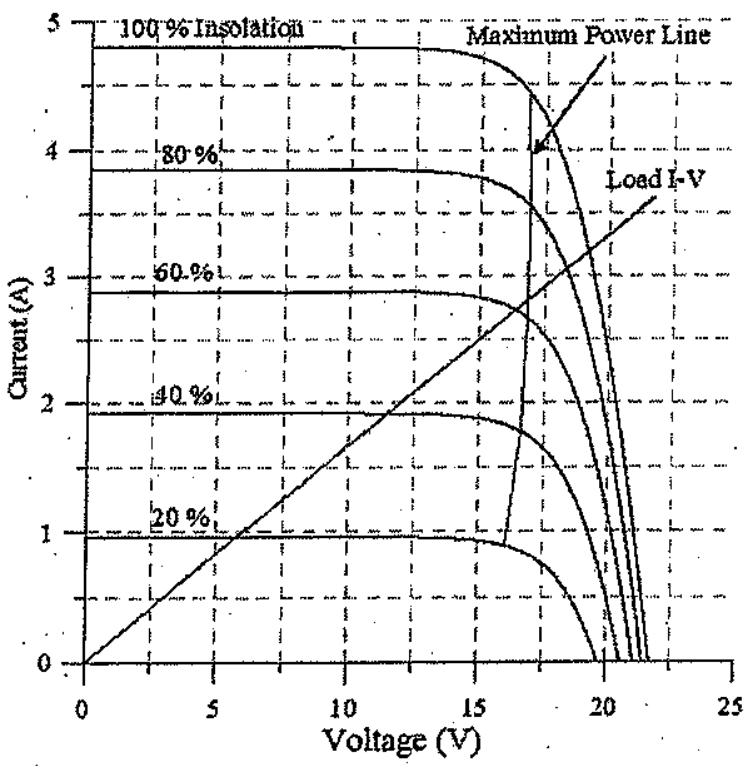

Fig. 3 Mismatching of I-V curves MPP and load line for PV generator.

Maximum power transfer theory stated the condition of maximum power delivered to the load, when the source internal impedance matches the load 
impedance. Thus, the resistance seen from the PV side of the converter needs to match the load resistance. By transferring the load resistance from load side of the converter to the PV side with a varying transformation ratio (D), the matching can be occurred.

Figure 3 shows a family of I-V curves of the PV array and one load resistance curve in the I-V plane. The mismatching between the MPP line of the array and the load line is obvious because the two lines are not corresponding to each other. The matching occurs only at the intersection point of the two lines. Using a buck-boost $\mathrm{DC} / \mathrm{DC}$ converter with varying duty ratio $\mathrm{D}$, a fully matching between the PV array and the load can be obtained.

\section{DC/DC CONVERTER TOPOLOGY}

The DC/DC converter may be buck, boost, or buckboost converter. $\mathrm{A}$ converter is required in the PV application for matching between the PV output voltage and the load voltage requirements. In this work a buck-boost converter is used for matching the PV output with the load input voltage for maximum power point tracking.

The buck-boost converters allow the output voltage to be greater or lower than the input voltage based on the switch duty "ratio D. There are many configuration of the buck-boost converter as CUK converter where the output voltage has inverted polarity to the input voltage. Also a single ended primary inductor converter (SEPIC) topologies where the output voltage has the same polarity as the input voltage.

The SEPIC converter is used in certain applications where the current drawn from the input is required to be relatively ripple-free [15-16]. A SEPIC converter has become popular in recent years in batterypowered systems that must step up or down depending upon the charge level of the battery [17]. In PV maximum power point tracking systems it must operate at certain point on the I-V curve without fluctuations around it to assure extraction of the maximum power from it. So that SEPIC converter topology is most appropriate in MPPT systems to operate at steady and ripple free current and voltage from the PV array.

\subsection{SEPIC Converter Principles}

The SEPIC converter [18-19] works in two modes: mode 1 where the transistor $(\mathrm{Q})$ is $\mathrm{ON}$ and mode 2 the transistor is OFF. The switching time period $T_{s}$ is divided into two sub periods; $\mathrm{DT}_{S}$ where the transistor switch is in the ON state and (1-D) $\mathrm{T}_{S}$ where the switch is in the OFF state. The basic circuit and the modes of operation of SEPIC converter are shown in Figure 4.

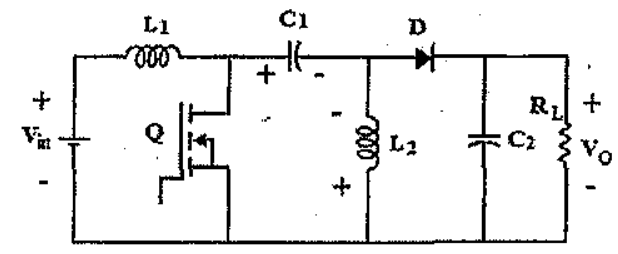

Basic Circuit

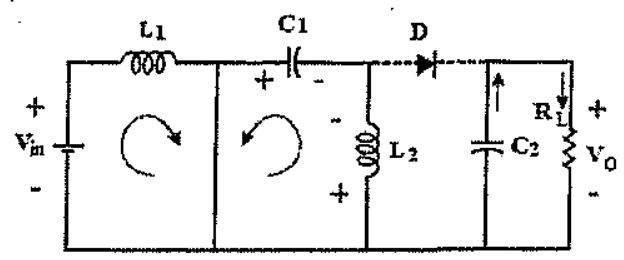

Mode $1(\mathrm{Q} O N)$

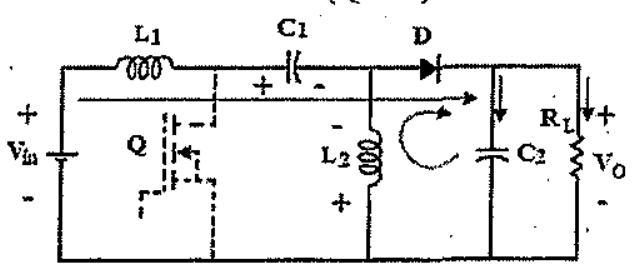

Mode 2 (Q OFF)

Fig. 4 The SEPIC DC/DC converter topology for buck-boost operation.

Taking into account that the average voltage across the inductor is zero, the capacitor $C_{1}$ average voltage $V_{C I}$ equals the input voltage $V_{\text {in }}$. The inductor $L_{2}$ is parallel to $\mathrm{C}_{1}$ during $\mathrm{ON}$ interval, so its voltage equals $\mathrm{V}_{\mathrm{C} 1}$. During OFF interval the inductor $\mathrm{L}_{2}$ voltage equals $\left(-\mathrm{V}_{\mathrm{O}}\right)$. This leads to the equation:

$D V_{\text {in }}=(1-D) V_{o}$

$\frac{V_{O}}{V_{\text {in }}}=\frac{D}{1-D}=k$

For an ideal converter, the current ratio is:

$\frac{I_{o}}{I_{\text {in }}}=\frac{1}{k}$

$R_{o}=\frac{V_{o}}{I_{o}}$, and $R_{\text {in }}=\frac{V_{\text {in }}}{I_{\text {in }}}$

$R_{o}=\frac{V_{o}}{I_{o}}=k^{2} \frac{V_{\text {in }}}{I_{\text {in }}}=k^{2} R_{\text {in }}$

$R_{\text {in }}=\frac{P_{\text {in }}}{I_{\text {in }}^{2}}$

$\left(R_{\text {in }}\right)_{\min }=\left(\frac{P_{\text {in }}}{I_{\text {in }}^{2}}\right)_{\max }$

$\left(R_{\text {in }}\right)_{\max }=\left(\frac{P_{\text {in }}}{I_{\text {in }}^{2}}\right)_{\min }$ 


$$
\begin{aligned}
& k_{\min }=\sqrt{\frac{R_{0}}{\left(R_{\text {in }}\right)_{\max }}} \\
& k_{\max }=\sqrt{\frac{R_{o}}{\left(R_{\text {in }}\right)_{\min }}} \\
& D=\frac{k}{1+k} \\
& D_{\max }=\frac{k_{\max }}{1+k_{\max }} \\
& D_{\min }=\frac{k_{\min }}{1+k_{\min }}
\end{aligned}
$$

\section{PROPOSED SYSTEM OVERVIEW}

The proposed MPPT circuit is composed of a PV system, resistive load, SEPIC converter, microcontroller system, transistor driving circuit, and measuring and monitoring system. The system block diagram is shown in Figure 5.

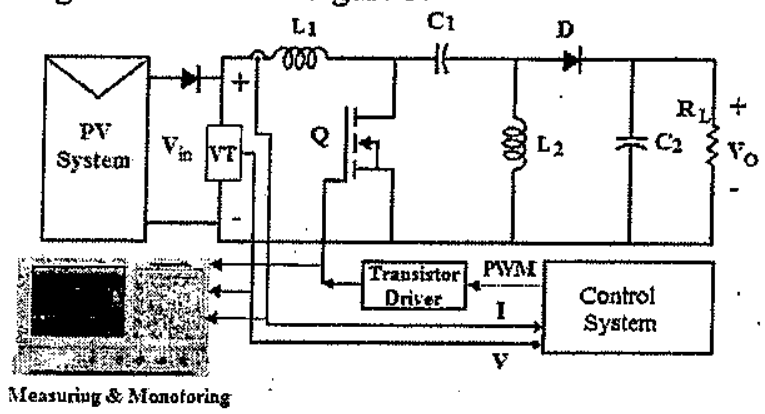

Fig. 5 Proposed MPPT system.

\subsection{The System Design}

The system design includes determining the load requirements, then $\mathrm{PV}$ array size, converter parameter design, and software development.

\subsubsection{Load requirements}

The load is assumed to be a resistive load of the following data: $R_{L}=6 \Omega, P_{L}=0: 80 \mathrm{~W}$. The load must absorb the maximum available power from the PV system at all operating conditions.

\subsubsection{PV system selection}

A suitable PV system is a single mono-crystalline photovoltaic solar module with the following data[20]:

It has 36 cells that can be configured as a single series branch or two parallel branches.

The module of 75W maximum power at standard test conditions (STC),

MPP voltage is $V_{m p}=17.1 \mathrm{~V}$,

Maximum power current is $I_{m p}=4.4 \mathrm{~A}$,
The open circuit voltage is $V_{o c}=21.7 \mathrm{~V}$ and

Short circuit current is $I_{s c}=4.8 \mathrm{~A}$.

\subsubsection{SEPIC converter design}

In a SEPIC design, the output voltage can be higher or lower than the input voltage. The SEPIC converter shown in Figure 4 uses, two inductors, $L_{1}$ and $L_{2}$. The two inductors can be wound on the same core since the same voltages are applied to them throughout the switching cycle. Using a coupled inductor takes up less space on the printed circuit board (PCB) and tends. to be lower cost than two separate inductors. The capacitor $C_{1}$ isolates the input from the output and provides protection against a shorted load.

\subsubsection{Duty cycle calculation}

Assume operating range of the PV array is between $20 \%$ and $100 \%$ insolation levels, then the maximum power of the array is between $14.28 \mathrm{~W}$ and $75 \mathrm{~W}$. the MPP current is between $0.888 \mathrm{~A}$ and $4.44 \mathrm{~A}$. From (Eq. 4 to Eq.16):

$$
\begin{aligned}
& \left(R_{\text {in }}\right)_{\min }=\left(\frac{P_{\text {in }}}{I_{\text {in }}^{2}}\right)_{\max }=\left(\frac{75}{(4.44)^{2}}\right)=3.8 \Omega \\
& \left(R_{\text {in }}\right)_{\max }=\left(\frac{P_{\text {in }}}{I_{\text {in }}^{2}}\right)_{\min }=\left(\frac{14.28}{(0.888)^{2}}\right)=18.1 \Omega \\
& k_{\min }=\sqrt{\frac{6}{18.1}}=0.576 \\
& k_{\max }=\sqrt{\frac{6}{3.8}}=1.257 \\
& D_{\min }=\frac{k_{\min }}{1+k_{\min }}=\frac{0.576}{1.576}=0.365 \\
& D_{\max }=\frac{k_{\max }}{1+k_{\max }}=\frac{1.257}{2.257}=0.557
\end{aligned}
$$

\subsubsection{Inductor selection}

The inductors $L_{1}$ and $L_{2}$ sizing are dependent on the switching frequency and the allowable current ripples. In MPPT systems, the stable operating point is required to minimize the oscillation around the maximum power point and losses occurs. So, the current ripple margin in the inductor must be as small as possible. It is assumed to be $2 \%$ of the input current. If the two coils are wound on the same core, the value of the inductance in next equation (17) is replaced by $2 \mathrm{~L}$ due to mutual inductance [18].

The peak input current at one sun $\left(1000 \mathrm{~W} / \mathrm{m}^{2}\right)$ is $4.44 \mathrm{~A}$, so the ripple current is:

$\Delta I_{L 1}=0.02 * 4.44=0.09 A$ 


$$
\begin{aligned}
& L_{1}=L_{2}=\frac{L}{2}=\frac{\left(V_{\text {in }}\right)_{\min }}{2^{*} \Delta I_{L}{ }^{*} f_{s w}}{ }^{*} D_{\max } \\
& L_{1}=L_{2}=\frac{16}{2^{*} 0.09^{*} 100^{*} 10^{3}} * 0.557=0.495 \mathrm{mH}
\end{aligned}
$$

The switching frequency $f_{s w}$ is assumed to be 100 $\mathrm{kHz}$. Adding a design margin of $20 \%$ the peak inductor current is:

$$
\begin{aligned}
& \left(I_{L_{1}}\right)_{\text {Peak }}=\left(I_{O}\right)_{\max } * \frac{\left(V_{o}\right)_{\max }+V_{D}}{\left(V_{\text {in }}\right)_{\min }} *(1.2) \\
& \left(I_{L_{1}}\right)_{\text {Peak }}=3.53 * \frac{21.16+0.5}{16} *(1.2)=5.73 \mathrm{~A} \\
& \left(I_{L_{2}}\right)_{\text {Peak }}=\left(I_{O}\right)_{\max } *(1.2) \\
& \left(I_{L_{2}}\right)_{\text {Peak }}=3.53 *(1.2)=4.24 \mathrm{~A}
\end{aligned}
$$

\subsubsection{MOSFET transistor selection}

At the $\mathrm{ON}$ state the transistor carries the two inductor currents. So the peak transistor current is:

$$
\begin{aligned}
& \left(I_{Q}\right)_{\text {Peak }}=\left(I_{L_{1}}\right)_{\text {Peak }}+\left(I_{L_{2}}\right)_{P_{\text {eak }}} \\
& \left(I_{Q}\right)_{\text {Peak }}=5.73+4.24=9.97 \equiv 10 \mathrm{~A}
\end{aligned}
$$

The RMS current of the MOSFET is:

$$
\begin{aligned}
& I_{R M S}=I \text { out } \sqrt{\frac{\left(V_{o}+V_{\text {in }(\min )}+V_{D}\right) x\left(V_{o}+V_{D}\right)}{V_{\text {in }(\min )}^{2}}} \\
& I_{R M S}=3.53 \sqrt{\frac{(21.16+16+0.5) x(21.16+0.5)}{16^{2}}} \cong 6.3 \mathrm{~A}
\end{aligned}
$$

The power dissipation in the transistor is the conduction losses plus the gate drive losses. The conduction loss, $\mathrm{P}_{\text {COND, }}$ is the $\mathrm{I}^{2} \mathrm{R}$ loss across the MOSFET. The maximum conduction loss is given by:

$$
P_{C O N D}=I_{R M S}^{2} x R_{D S(O N)}{ }^{x D_{\max }}
$$

The gate drive losses of the MOSFET are given by the gate current $I_{G}$ and the gate drive voltage $V_{D R}$ as:

$$
P_{\text {Drive }}=I_{G} x V_{D R}
$$

The amount of gate current required to turn the MOSFET on can be calculated using the formula [21]:

$$
I_{G}=Q_{G} x f_{s w}
$$

A transistor IRFP460 is selected where

$$
\begin{aligned}
& R_{D S(O N)}=0.27 \Omega, Q_{G}=210 \mathrm{nc} \\
& P_{C O N D}=6.3^{2} \times 0.27 \times 0.557=5.97 \mathrm{~W} \\
& I_{G}=(210 \mathrm{nc}) \times(100 \mathrm{kHz})=0.021 \mathrm{~A} \\
& P_{\text {Drive }}=0.021 \times 10=0.21 \mathrm{~W} \\
& P_{\text {LOSS }}=P_{C O N D}+P_{\text {Drive }}=5.97+0.21=6.18 \mathrm{~W}
\end{aligned}
$$

The transistor's peak reverse voltage is :

$$
\begin{aligned}
\left(V_{Q}\right)_{P R V} & =\left(V_{\text {in }}\right)_{\max }+\left(V_{O}\right)_{\max } \\
& =16.85+21.16=38.01 \mathrm{~V}
\end{aligned}
$$

\subsubsection{Power diode selection}

The diode $\mathrm{D}$ carries the same current in the main switch Q. It must also withistand the maximum reverse voltage on it.

$$
\begin{aligned}
& \left(I_{D}\right)_{P e a k}=\left(I_{Q}\right)_{P e a k}=10 \mathrm{~A} \\
& \left(V_{D}\right)_{P R V}=\left(V_{i n}\right)_{\max }+\left(V_{o}\right)_{\max } \\
& \left(V_{D}\right)_{P R V}=16.85+21.16=38.01 \mathrm{~V}
\end{aligned}
$$

\subsubsection{Input capacitor selection}

Hence, the input current waveform is continuous and triangular. The inductor ensures that the input capacitor sees fairly low ripple currents. The RMS current in the input capacitor is given by [18]:

$$
\begin{aligned}
& \left(I_{C 1}\right)_{R M S}=\frac{\Delta I_{L}}{\sqrt{12}} \\
& \left(I_{C 1}\right)_{R M S}=\frac{0.09}{\sqrt{12}}=0.026 \mathrm{~A}
\end{aligned}
$$

Although the input capacitor is not so critical in SEPIC application, a $10 \mu \mathrm{F}$ or higher value, good quality capacitor would prevent impedance interactions with the input supply.

\subsection{Tracking Controller}

The proposed control algorithm is based on the hill climbing method. At varying insolation level, the changing in the array voltage at maximum power is so small, whereas large range is available in the array current or array power. So that taking the array current as a reference is clear and more accurate than depending on the array voltage. Also in the ascending or descending modes of insolation level a care is taken when transferring from curve to another in determining the starting point at the new curve of the new insolation level to realize the convergence.

\subsection{Program Flowchart}

The program begins with initial value of the duty cycle (D) equals 0.5 so the output voltage equals the input voltage. The program measures the current and voltage of the PV module, then calculates the power extracted from it. Then it checks the change in the 
output power to increase or decrease the reference current of the module to calculate the newer duty cycle (D). The program generates the PWM signal that applied to the converter and repeats the cycle. A saturation limiter is used to limit the duty cycle from minimum to maximum allowable values.

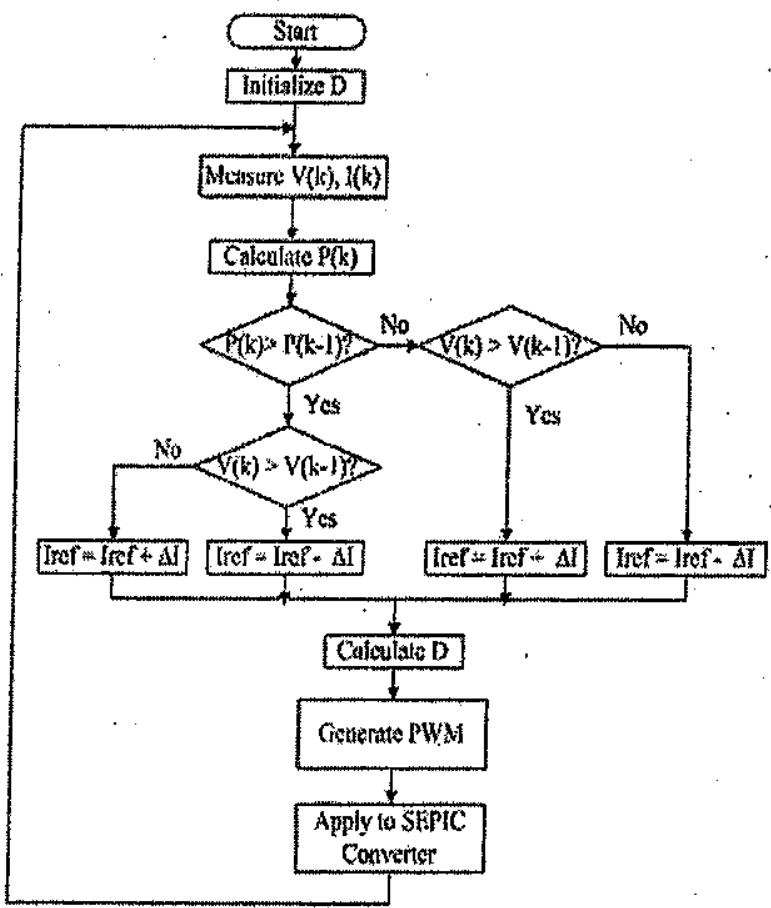

Fig. 6 Flowchart of the MPPT algorithm.

\section{SIMULATION RESULTS}

Simulation results include testing on suddenly changing of the environmental conditions as solar insolation and /or temperature, and the load resistance changing. At all these conditions the system must track the maximum power generated from the PV array. So we can see from figures blow that the power extracted from the PV module is fixed at maximum available power if the environmental conditions or load are changed.

Also with varying insolation level, the current and voltage of the PV module are adopted to extract the maximum power.

\subsection{Changing in Insolation Results}

To test the controller performance a changing may increase or decrease the insolation level. To test the insolation level increasing, it is suddenly changed from $60 \%$ to $80 \%$ then to $100 \%$ insolation level. Also, to test the insolation level decreasing case, insolation is suddenly changed in reverse order.

\subsubsection{Increasing the insolation level}

Figures 7 and 8 show the operating point movement on $I-V$ and $P-V$ curves of the PV module respectively.
The movement from starting point 0 to maximum power point $I$ at $60 \%$ insolation level curve. Then if the insolation level is increased from $60 \%$ to $80 \%$, then $100 \%$, the controller moves towards point 2 then point 3 that represent the maximum power point on their curves.

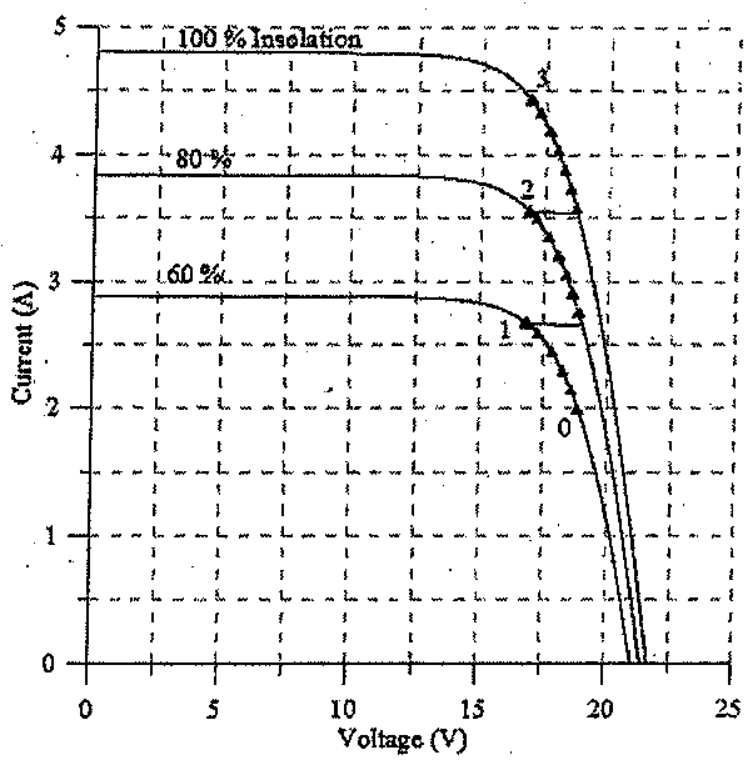

Fig. 7 Controller performance at I-V plane for increasing insolation level.

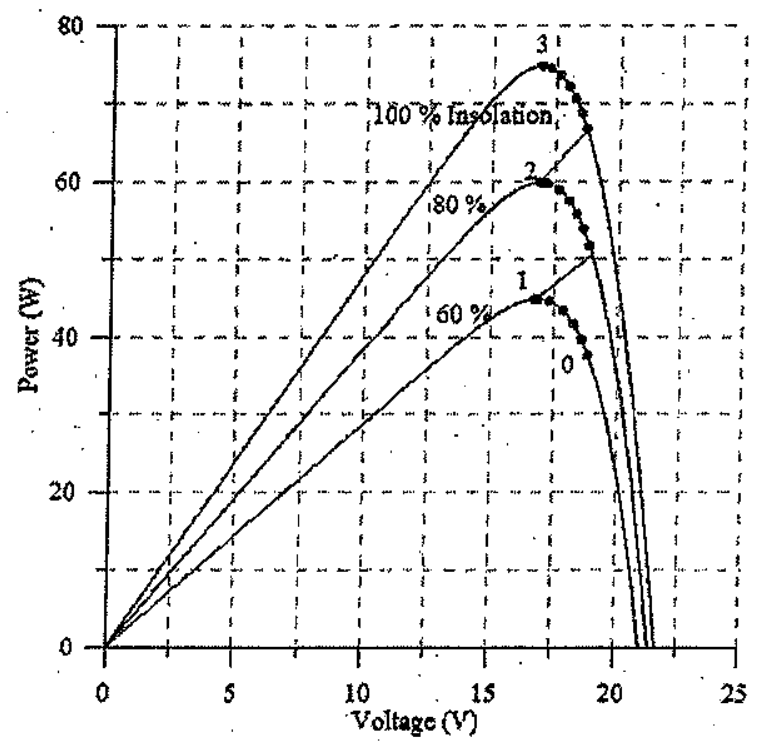

Fig. 8 Controller performance at P-V plane for increasing insolation level.

Figure 9 shows the power extracted from the PV module is increased to its maximum value. It is shown that as the insolation increased the duty ratio increased to increase the input current and input power that corresponds the maximum power.point. 


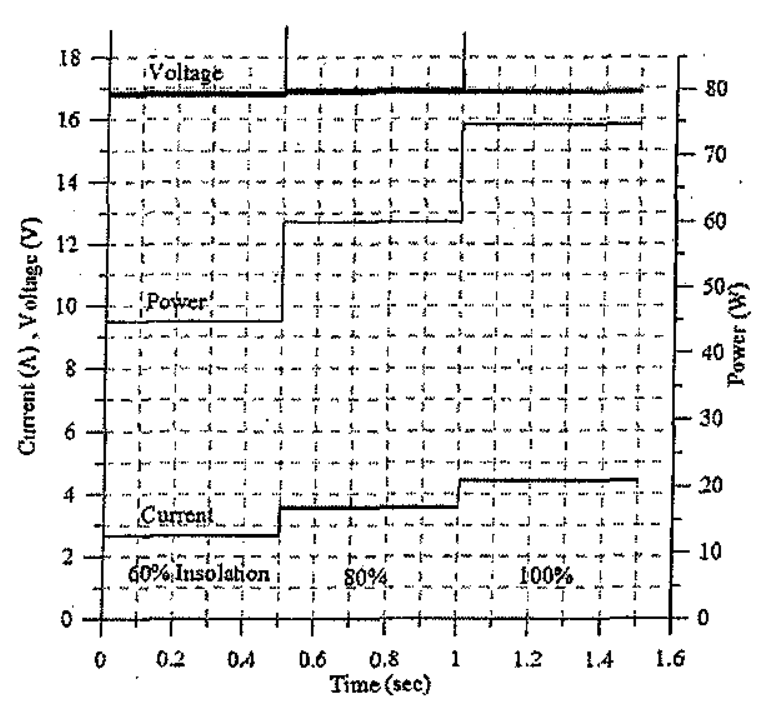

Fig. 9 PV module output (V, I, and P) with suddenly increasing insolation level in steps.

\subsubsection{Decreasing the insolation level}

Figures 10 and 11 indicate the performance of the controller to follow up the insolation changing in decreasing case.

Figure 10 shows the performance applying on $\mathrm{I}-\mathrm{V}$ curves of the PV module, whereas figure 11 shows performance on P-V curves. Point 0 is the starting point on $100 \%$ insolation curve, the operating point moves towards point 1 (MPP on the curve). The insolation level is step changed to $80 \%$ then to $60 \%$. The controller moves the operating point to point 2 , then to point 3 that represent the maximum power points on the corresponding curves.

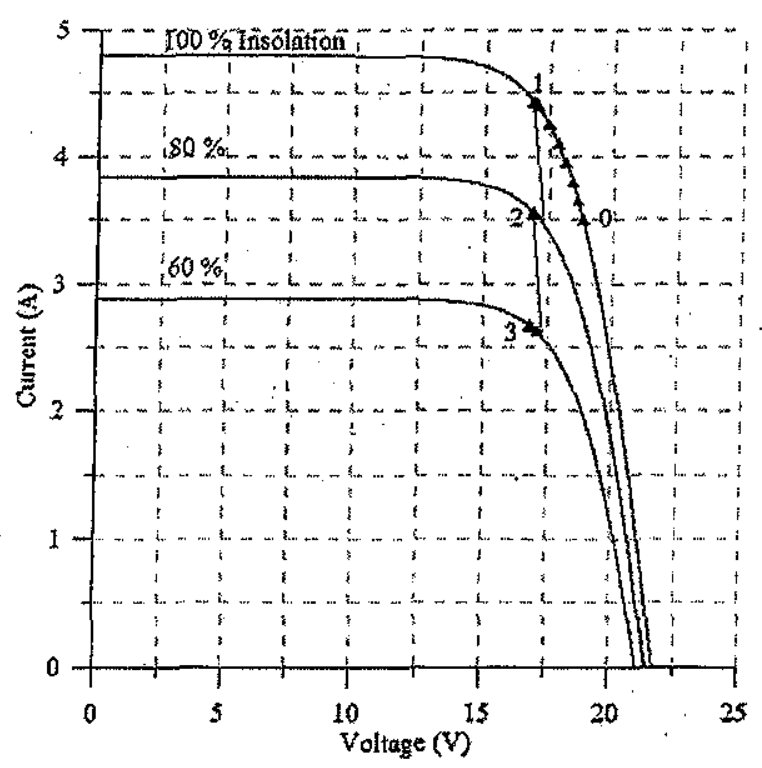

Fig. 10 Controller performance at $I-V$ plane for decreasing insolation level.

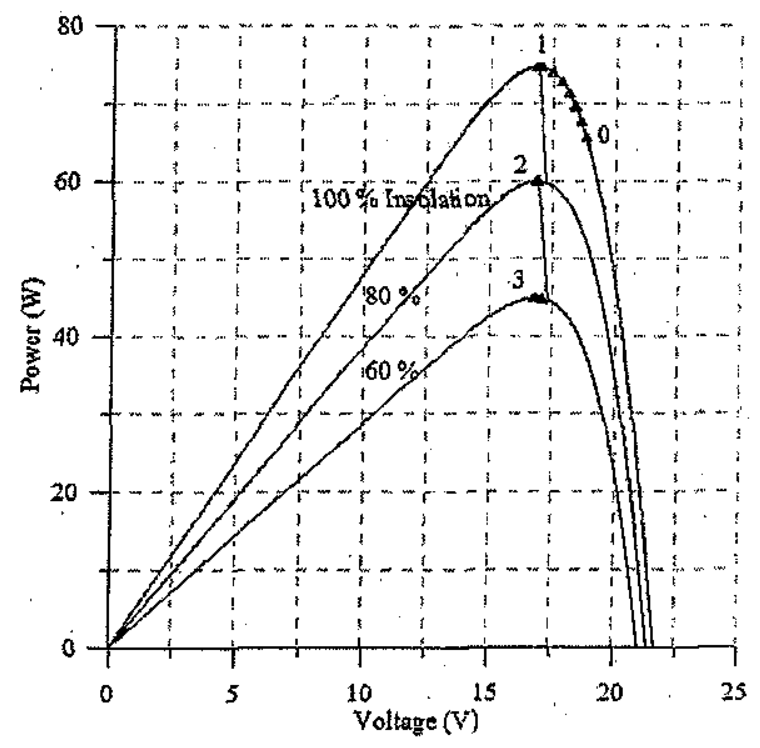

Fig. 11 Controller performance at $P-V$ plane for decreasing insolation level.

Figure 12 indicates the PV module output voltage, current and power with varying insolation levels. It is obvious that the current and power are proportional varying with the insolation whereas the voltage changes is small.

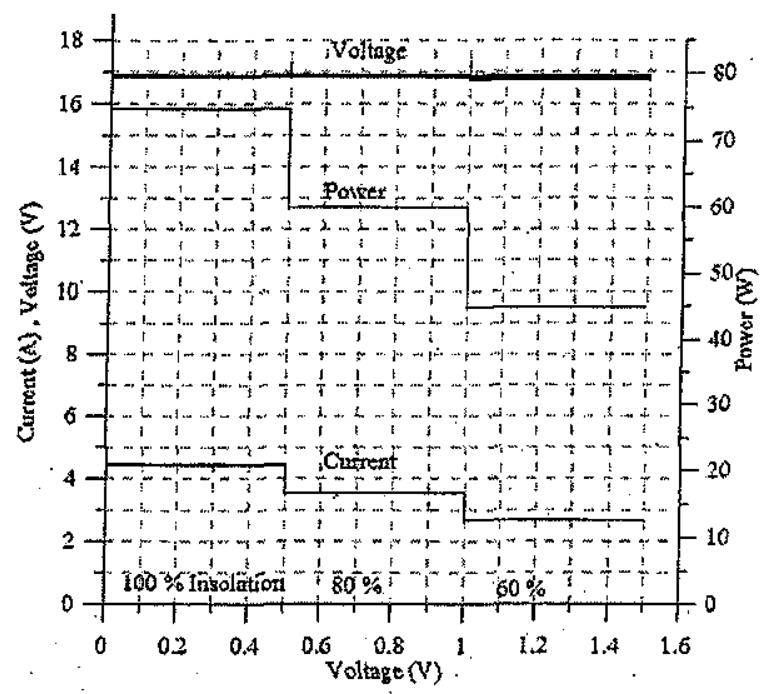

Fig. 12 PV array output with suddenly decreasing insolation level in steps.

Figure 13 shows the effect of insolation level variation on duty ratio (D) and the effects of this variation on the input load resistance while the load resistance is fixed.

The PWM control signal $\left(\mathrm{V}_{\mathrm{C}}\right)$ is shown in Figure 14 at variable insolation level. At $100 \%$ insolation level the duty ratio is at its maximum value $(0.557)$ as expected in the analysis section. 


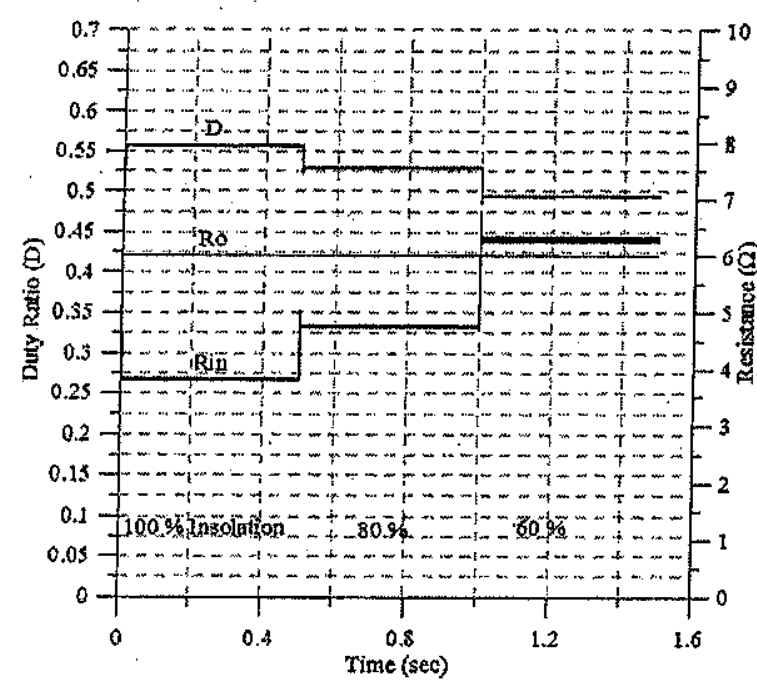

Fig. 13 Controller duty ratio (D), load resistance $\left(R_{0}\right)$, input resistance $\left(R_{i n}\right)$ at various insolation levels.

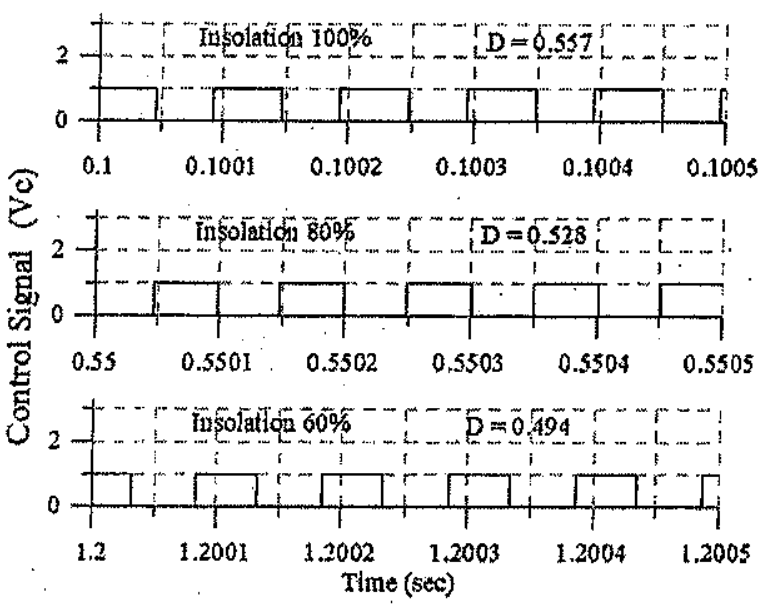

Fig. 14 PWM control signal $(\mathrm{Vc})$ at various insolation levels.

\subsection{Changing in Load Results}

Another test for the proposed MPPT system operation is the load resistance variation as shown in Figure 15 . As the load varies, the duty ratio must be varied to match the load resistance with the PV module output, consequently the output voltage and current vary. The input voltage, current and power are persist at maximum power point

\section{CONCLUSIONS}

A novel MPPT for standalone PV system is proposed and simulated in this work. The PV system model and characteristics is introduced and the problem of mismatching is advised and explained. A proposed control algorithm is simulated and applied to a SEPIC converter to extract the maximum power from the PV array regardless of the load or environmental conditions. The converter is designed according the load requirements. The simulation results are divided into three sections; increasing, decreasing of the insolation level, and load resistance variations. In all of the three cases, the controller proven that it is excellent in tracking and extracting the maximum power from the PV array irrespective of the surrounding conditions or load variations.

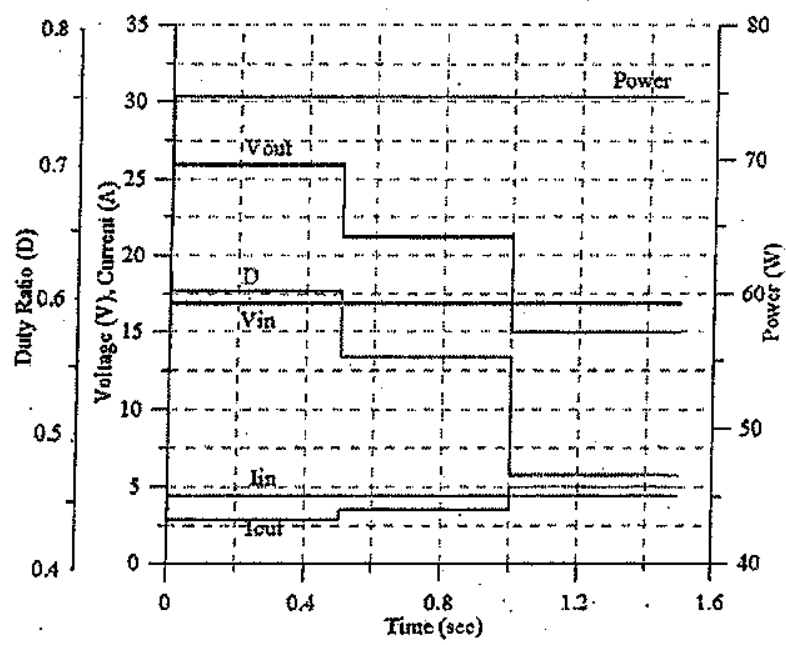

Fig. 15 Controller performance when changing in load resistance; from left to right $9 \Omega, 6 \Omega$, and $3 \Omega$.

\section{REFERENCES}

[1] C. Hua, and C. Shen, "Implementation of a DSPControlled Photovoltaic System with Peak Power Tracking", IEEE Trans. On Industrial Electronics, Vol. 45, No. 1, Feb. 1998.

[2] T. Esram, and P. Chapman. "Comparison of Photovoltaic Array Maximum Power Point Tracking Techniques", IEEE Transactions On Energy Conversion, Vol. 22, No. 2, June 2007.

[3] T. Senjyu, T. Shirasawa, K. Uezato ,"A Maximum Power Point Tracking Control for Photovoltaic Array without Voltage Sensor "Journal of Power Electronics (JPE), vol. 2, no. 3, pp.155-161, 2002.

[4] W. Xiao and W. G. Dunford, "A modified adaptive hill climbing MPPT method for photovoltaic power systems," in Proc. 35th Annu. IEEE Power Electron. Spec. Conf., 2004.

[5] C.-C. Hua and J.-R. Lin, "Fully digital control of distributed photovoltaic power systems," in Proc. IEEE Int. Symp. Ind. Electron., 2001, pp. $1-6$.

[6] K. H. Hussein and 1. Mota, "Maximum photovoltaic power tracking: An algorithm for rapidly changing atmospheric conditions," in IEE Proc. Generation Transmiss. Distrib., 1995

[7] .G. W. Hart, H. M. Branz, and C. H. Cox, "Experimental tests of open loop maximumpower-point tracking techniques," Solar Cells, vol. 13, 1984. 
[8] B. Bekker and H. J. Beukes, "Finding an optimal PV panel maximum power point tracking method," in Proc. 7th AFRICON Conf. Africa, 2004.

[9] N. Gounden, S. Peter, H. Nallandula, S. Krithiga, "Fuzzy logic controller with MPPT using line-commutated inverter for three-phase grid-connected photovoltaic systems" Renewable Energy 34 (2009) 909-915.

[10] Hussein, K. Hirasawa, J. Hu, and J. Murata, "The dynamic performance of photovoltaic supplied dc motor fed from DC-DC converter and controlled by neural networks," in Proc. Int. Joint Conf. Neural Network, 2002.

[11] P. Midya, P. T. Krein, R. J. Turnbull, R. Reppa, and J. Kimball, "Dynamic maximum power point tracker for photovoltaic applications," in Proc. 27th Annu. IEEE Power Electron. Spec. Conf., 1996, pp. 1710-1716.

[12] Abo-Khalil, D. Lee, J Choi, H. Kim, "Maximum Power Point Tracking Controller Connecting PV. System to Grid", Journal of Power Electronics (JPE), vol. 6, no. 3, pp.226234, 2006

[13] H. Bae, J. Park, B. Cho, G. Yu "New MPPT Control Strategy for Two-Stage Grid-Connected Photovoltaic Power Conditioning System" Journal of Power Electronics (JPE), vol. 7, no. 2, pp.174-180, 2007.
[14] E. Matagne, Chenni R, El Bachtiri R., "A photovoltaic cell model based on nominal data only", International Conference on Power Engineering, Energy and Electrical Drives, 2007. Powereng 2007. 12-14 April 2007 Setubal, Portugal.

[15] K. Rajashekara, S. Bhat; B. Bose, "Power Electronics; The Electrical Engineering Handbook", CRC Press LLC, 2000.

[16] L. TIMOTHY, SKVARENINA "The'Power Electronics Handbook", Industrial Electronics, CRC PRESS Boca Raton London New York Washington, D.C.

[17] R. Ridley, "Analyzing the SEPIC Converter", Power Systems Design Europe, November 2006

[18] W. Gu, Dongbing Zhang, "Designing A SEPIC Converter", National Semiconductor Application Note 1484, April 30, 2008.

[19] J. Falin ,"Designing DC/DC converters based on SEPIC topology", Power Management -Texas Instruments Incorporated, High-Performance Analog Products, Analog Applications Journal, 2008.

[20] Shell Products, SQ75Solar Cell Information Sheet, http://www.shell.com/

[21] National Semiconductor "LM3478 High Efficiency Low-Side N-Channel Controller for Switching Regulator" Datasheet National Semiconductor Corporation, 2001 . 